\title{
Osteosarcoma in Dogs: Diagnosis and Treatment - A Literature Review
}

Paula de Sanctis $^{1 *}$, Brunno Felipe Ramos Caetano', Luis Mauricio Montoya Flórez ${ }^{2,3}$, Valéria Barsosa de Souza ${ }^{4}$, Willian Fernando Zambuzzi ${ }^{5}$ and Noeme Sousa Rocha ${ }^{3 *}$

${ }^{1}$ College of Medicine from Botucatu, São Paulo State University (UNESP), Campus (Botucatu), 18681-687, São Paulo, Brazil

${ }^{2}$ Gidimevetz, Pedagogical and Technological University of Colombia (Pathology Research Group), Caldas University, Manizales, Colombia

Investigative and Comparative Pathology Laboratory, College of Veterinary Medicine and Animal Husbandry, São Paulo State University (UNESP), Campus (Botucatu), 18618-681, São Paulo, Brazil

${ }^{4}$ Department of Pharmacology, UNICAMP - Campinas State University, Campinas, 13083-859, São Paulo, Brazil

${ }^{5}$ Bioassays and Cell Dynamics Laboratory, Biosciences Institute, São Paulo State University (UNESP), Campus (Botucatu), 18618-689, São Paulo, Brazil

\begin{abstract}
Among primary bone tumors, osteosarcoma (OSA) is the most diagnosed in dogs. OSA is a highly aggressive tumor and metastatic spread to the lungs contributes to the poor prognosis. Surgery followed by adjuvant chemotherapy and radiation therapy is the current treatment of choice for this disease. However, surgery is not applied in all cases because dog owners disagree with partial or total amputation of the limb. Due to the aggressiveness of the disease, this review aims to gather information about the biological bases of the OSA, to discuss its diagnosis and treatment as well as to serve as an instrument in comparative oncological research encouraging effective diagnostic and therapeutic approaches to be improved and discovered.
\end{abstract}

Keywords: Osteosarcoma; Dog; Diagnosis; Treatment; Personalized medicine

\section{Introduction}

Among primary bone tumors, osteosarcoma (OSA) is the most diagnosed in dogs, approximately 80 to $85 \%$ of cases and represents 3 to $4 \%$ of all tumors that occur in these animals. The appendicular skeleton is the most common site affected, in middle age to elderly dogs and medium to large size [1-15].

Furthermore, OSA is a highly aggressive neoplasm characterized by direct synthesis of osteoid $[1,8,9,14,15]$ and metastatic spread to the lungs, contributing to poor prognosis [1-3,12]. The canine OSA is histologically and molecularly similar to those in humans and is considered an excellent comparative model, [1,3,6,9,16,17] in addition to the fact that animals share the same environment as their owners $[3,6,16]$. The diagnosis is based on clinical history and physical examination, as well as additional imaging exams, which involve radiography, ultrasound, bone scintigraphy, and computed tomography. Cytopathological and histopathological exams are extremely important to confirm the diagnosis $[1,4,7,15,18]$. Limb amputation followed by adjuvant chemotherapy and radiation therapy is the current treatment of choice for canine OSA [1,2,5-10,12-15,1921]. However, dog owners disagree with partial or total amputation of the limb, causing difficulty in the treatment and worsening the clinical condition.7 Chemotherapy with doxorubicin, cisplatin, carboplatin alone or in combination is used to minimize the risk of developing metastases [1,6,22] and increase survival time [11,20-24]. On the other hand, radiation therapy is used for local control and analgesia $[1,5,13,22]$.

Attempts to improve the prognosis led to the search for new diagnostic and surgical techniques, identification of molecular pathways, drugs or substances that could be associated with existing treatments and combinations of therapies. Although some progress in this area has been achieved, it is still necessary to apply discover new biomarkers and combine this knowledge in the design of new molecules in multidisciplinary approach, improving the diagnostic, prognosis and therapeutic approaches. It is also noteworthy the importance of a professional who is very present in human medicine, the care manager, who makes a link between the medical team and the patient, so that the team works as partners. This professional informs the patient about his health condition in a clear way and makes him more involved in the treatment, being able to manage his own health, with changes of life habits in order to improve his prognosis [25-29]. In veterinary medicine, this professional is still not very present, especially in developing countries, and changes in patient's life habits depend on the actions of their owner, since he is responsible for their eating and physical activities outside the home environment.

Thus, this manuscript aims to gather information about the biological bases of the OSA, to discuss its diagnosis and treatment to serve as an instrument in comparative oncology research and to encourage effective diagnostic and therapeutic approaches to be improved or discovered.

For this purpose, a literature review was elaborated in the databases Scielo, Lilacs, PubMed-NCBI and BMC between the periods of 2000 to 2017. The keywords osteosarcoma and dog had been used and only the articles involving either diagnosis and treatment or both were selected. Case reports with a low number of animals, with the exception of one study found in Scielo, were excluded. A total of 1349 articles were found. After reading the titles of these articles, it was verified that some of them were repeated in the different bases. From these repetitions the articles were counted only once.

Finally, 290 articles were selected, and with the reading of the abstracts, 63 articles were selected to read the full text, of these [27], were used, as they followed the objective of this study. The incidence of

*Corresponding author: Paula de Sanctis, College of Medicine from Botucatu, São Paulo State University (UNESP), Campus (Botucatu), 18681-687, São Paulo, Brazil, Tel: +551499109-7926; E-mail: paulinhasanctis@gmail.com

Received August 20, 2017; Accepted September 12, 2017; Published September 20, 2017

Citation: de Sanctis P, Caetano BFR, Flórez LMM, de Souza VB, Zambuzzi WF, et al. (2017) Osteosarcoma in Dogs: Diagnosis and Treatment - A Literature Review. J Cytol Histol 8: 473. doi: 10.4172/2157-7099.1000473

Copyright: (c) 2017 de Sanctis P, et al. This is an open-access article distributed under the terms of the Creative Commons Attribution License, which permits unrestricted use, distribution, and reproduction in any medium, provided the original author and source are credited. 
Citation: de Sanctis P, Caetano BFR, Flórez LMM, de Souza VB, Zambuzzi WF, et al. (2017) Osteosarcoma in Dogs: Diagnosis and Treatment - A Literature Review. J Cytol Histol 8: 473. doi: 10.4172/2157-7099.1000473

Page 2 of 5

OSA in dogs, the techniques used in the diagnosis and treatment of in vivo and in vitro studies are described in chronological order in Table 1.

\section{Incidence of Osteosarcoma in Dogs}

$55 \%$ of the studies mention that the appendicular skeleton is predominantly the most affected site of OSA. These are: Chen at. Al [2-5,7-14]. The animals described in this review, the animals were middle aged to elderly and medium to large size, except for one case of a Maltese dog reported by Teixeira et al. [18].

\section{Cytopathological and Histopathological Approach in the Diagnosis of Osteosarcoma}

The diagnosis of canine osteosarcoma is performed by cytopathological examination and confirmed through tumor biopsy followed by histopathological examination. However, some authors such as Teixeira et al. [18] emphasize the necessity to develop less invasive techniques, since incisional biopsy can cause pathological fractures and complications in healing. To reduce such complications,

\begin{tabular}{|c|c|c|c|}
\hline Authors & $\begin{array}{l}\text { Incidence of } \\
\text { OSA (\%) }\end{array}$ & Diagnostic method & Treatment method \\
\hline Chun et al. [11] & $\mathrm{N} / \mathrm{F}$ & $\begin{array}{l}\text { Physical and histopathological examination, thoracic } \\
\text { radiographs, } \mathrm{CBC}^{*} \text {, serum biochemistry profile and } \\
\text { urinalysis }\end{array}$ & Chemotherapy with cisplatin/doxorubicin \\
\hline Garzotto et al. [21] & $N / F$ & $\begin{array}{l}\text { Histopathological examination and radiography for check } \\
\text { the presence of metastasis }\end{array}$ & $\begin{array}{l}\text { Limb amputation followed chemotherapy with doxorrubicin and } \\
\text { cisplatin }\end{array}$ \\
\hline Dickerson et al. [22] & $N / F$ & $\begin{array}{l}\text { Physical exam, } \mathrm{CBC}^{*} \text {, radiographs, chemistry panel, } \\
\text { histopathological examination and } \mathrm{CT}^{*}\end{array}$ & $\begin{array}{l}\text { Surgery, chemotherapy, radiation therapy or some combination of } \\
\text { these therapies for dogs over } 15 \mathrm{~kg} \text { with histologic confirmation. } \\
\text { Cobalt } 60 \text { photons with either a palliative or definitive fractionation } \\
\text { scheme were used to deliver radiation therapy. }\end{array}$ \\
\hline Kirpensteijn et al. [15] & $N / F$ & $\begin{array}{l}\text { FNAB }^{*} \text {, measure of the } \mathrm{AP}^{*} \text { level and histopathological } \\
\text { examination using a new classification system }\end{array}$ & Surgical excision and chemotherapy \\
\hline Bailey et al. [20] & $N / F$ & $\begin{array}{l}\text { Physical examination, } \mathrm{CBC}^{*} \text {, chemistry panel, urinalysis, } \\
\text { regional skeletal radiographs, and 3-view thoracic } \\
\text { radiographs. } \\
\text { Presurgical FNA* of the tumor, biopsy of the tumor, or } \\
\text { both were performed in most but not all patients }\end{array}$ & $\begin{array}{l}\text { Surgery followed by adjuvant chemotherapy with carboplatin and } \\
\text { doxorubicin }\end{array}$ \\
\hline DeRegis et al. [24] & $N / F$ & Histopathological examination & $\begin{array}{l}\text { Limb amputation followed chemotherapy with cisplatin and } \\
\text { doxorubicin (using different doses) after } 2 \text { or } 10 \text { days after surgery }\end{array}$ \\
\hline Ziliotto et al. [7] & $N / F$ & $\mathrm{~N} / \mathrm{F}$ & Cortical bone allogeneic implant preserved in glycerin \\
\hline Ferrigno et al. [8] & $N / F$ & $\begin{array}{l}\text { Radiography: Chest } \mathrm{x} \text {-ray and abdominal ultrasound } \\
\text { were performed to check the presence of metastases }\end{array}$ & $\begin{array}{l}\text { Limb amputation and prothesis placement followed chemotherapy } \\
\text { with doxorrubicin and carboplatin }\end{array}$ \\
\hline Kow et al. [9] & 85 & $\mathrm{~N} / \mathrm{F}$ & Limb amputation and adjuvant chemotherapy \\
\hline Kirpensteijn et al. [10] & $N / F$ & Radiography and histopathological examination & Limb amputation \\
\hline Teixeira et al. [18] & $N / F$ & $\begin{array}{l}\text { Radiography, FNA* and histopathological examination by } \\
\text { FNA fixed in formalin }\end{array}$ & $\mathrm{N} / \mathrm{F}$ \\
\hline Sottnik et al. [23] & $\mathrm{N} / \mathrm{F}$ & $\begin{array}{l}\text { 3-view thoracic radiographs and scintigraphy to check the } \\
\text { presence of metastases }\end{array}$ & $\begin{array}{l}\text { Limb amputation and adjuvant chemotherapy with doxorubicin or } \\
\text { carboplatin or both }\end{array}$ \\
\hline Biller et al. [27] & $\mathrm{N} / \mathrm{F}$ & $\mathrm{N} / \mathrm{F}$ & $\begin{array}{l}\text { Limb amputation followed adjuvant chemotherapy with carboplatin } \\
\text { or carboplatin/doxorubicin }\end{array}$ \\
\hline O’Donoghue et al. [6] & $\mathrm{N} / \mathrm{F}$ & $\mathrm{N} / \mathrm{F}$ & $\begin{array}{l}\text { Limb amputation followed by doxorubicin or platinum-based drug } \\
\text { chemotherapy }\end{array}$ \\
\hline McMahon et al. [12] & $\mathrm{N} / \mathrm{F}$ & Histopathological examination & $\begin{array}{l}\text { Limb amputation followed chemotherapy with carboplatin or } \\
\text { caboplatin/gemcitabine }\end{array}$ \\
\hline Wittenburg et al. [17] & $\mathrm{N} / \mathrm{F}$ & $\mathrm{N} / \mathrm{F}$ & $\begin{array}{l}\text { Cell culture assay treated with } \mathrm{HDACi}^{*}\left(\mathrm{VPA}{ }^{*}\right) \text {, VPA/proteasome } \\
\text { inhibitor ONX0912 and VPA/mitomycin C }\end{array}$ \\
\hline Karnik et al. [14] & $\mathrm{N} / \mathrm{F}$ & Histopathological examination and radiography & $\mathrm{CT}^{*}$ to determine surgical margins for limb-sparing surgery \\
\hline Selvarajah et al. [25] & $\mathrm{N} / \mathrm{F}$ & Histopathological examination & $\begin{array}{l}\text { Limb amputation chemotherapy with carboplatin or carboplatin/ } \\
\text { doxorubicin or carboplatin/cisplatin }\end{array}$ \\
\hline Monks et al. [16] & $N / F$ & Histopathological examination and radiography & Limb amputation \\
\hline Selmic et al. [19] & $\mathrm{N} / \mathrm{F}$ & $\begin{array}{l}\text { Thoracic radiographs or } \mathrm{CT}^{*} \text { and histopathological } \\
\text { examination }\end{array}$ & $\begin{array}{l}\text { Limb amputation followed adjuvant chemotherapy with carboplatin } \\
\text { or doxorubicin-based or both }\end{array}$ \\
\hline Wycislo and Fan [3] & 85 & Histopathological examination & Retrospective study \\
\hline Talbott et al. [13] & $N / F$ & $\begin{array}{l}\text { Cytopathological and/or histopathological examination } \\
\text { plus whole body } \mathrm{CT}^{\star} \text { scan (used to diagnosis metastasis) }\end{array}$ & $\mathrm{N} / \mathrm{F}$ \\
\hline Cannon et al. [26] & $N / F$ & $\mathrm{~N} / \mathrm{F}$ & Cell culture assay treated with Aurora kinase inhibitors \\
\hline Mantovani et al. [5] & 85 & $\mathrm{~N} / \mathrm{F}$ & Radiation therapy and radiation therapy with Erlotinib \\
\hline Gôuvea et al. [2] & 85 & $\begin{array}{l}\text { Medical History, Physical Examination, Radiological } \\
\text { Findings, histopathological Examination Confirmed The } \\
\text { diagnosis }\end{array}$ & Limb amputation followed by chemotherapy with carboplatin \\
\hline Murphy et al. [1] & 80 to 85 & $N / F$ & $\begin{array}{l}\text { Limb amputation followed by chemotherapy with carboplatin and } \\
\text { doxorubicin }\end{array}$ \\
\hline Sabattini et al. [4] & 85 & FNA $^{*}$ and histopathological examination & $\mathrm{N} / \mathrm{F}$ \\
\hline
\end{tabular}

N/F: No Information. *CBC: Complete Blood Count; CT: Computed Tomography; FNA/FNAB: Fine-Needle Aspiration/Fine-Needle Aspiration Biopsy; AP: Plasma Alkaline Phosphatase; HDACi: Histone Deacetylase Inhibitors; VPA: Valproic Acid.

Table 1: Incidence of OSA (\%), diagnostic and treatment methods used, results of the articles according to the authors. 
these authors proposed the fixation of fine needle aspiration (FNA) material in formalin for use in histopathological examination. The results obtained from this procedure were promising.

In addition to being less invasive, the cytopathological examination has several advantages over histopathological examination because it is simple to perform, low cost and provide quick results. When comparing these exams, Sabattini et al. [4] did not consider their results completely satisfactory, since they observed 1 false positive and 8 false negative in the cytopathological examination against no false positive and 5 false negative on the histopathological examination. Nonetheless, these authors acknowledge that cytopathological examination results may be more reliable if the technique is improved. A possible solution is pointed out by Teixeira et al. [18] and consists of the FNA in more than one point. Another solution would be to carry out the histopathological examination only in case of diagnostic doubts.

\section{Surgical Approach and Diagnosis through Imaging Tests}

Radiographic examinations, bone scans and tomography improve the diagnosis, especially to investigate metastases and other diseases, as presented in the studies of Garzotto et al. [21] Sottnick et al. [23] and Talbott et al. [13]. The study by Ferrigno et al. [8] still includes abdominal ultrasound. The dentification of metastases and other diseases is fundamental to planning the treatment and, consequently, obtaining better prognosis $[13,14,21,23]$ Regarding the treatment, Ferrigno et al. [8] and Gôuvea et al. [2], reported that limb preservation surgery, considered to be the best choice of treatment, as well as emphasized by Ziliotto et al. [7], when combined with adjuvant chemotherapy provided a longer survival. In addition, the study by Ziliotto et al. [7] has improved the surgical technique focused on the preservation of the bone implant in glycerin, which proved to be efficient for this purpose. However, the main obstacle for surgery proceedings is to define the surgical margins. For this objective Karnik et al. [14] evaluated whether computed tomography would be efficient to delimit these margins. The results were not satisfactory, suggesting that other techniques should be used, such as magnetic resonance imaging, bone scintigraphy and positron emission tomography (PET scan). Bone scintigraphy, for example, could be a more viable option, since it allows evaluation of the whole skeleton of the patient with high sensitivity and low doses of ionizing radiation, along with the fact it is efficient for the detection of metastases because the radiopharmaceutical used (usually glucose labeled with Fluorine-18) accumulate in the bones. However, imaging tests are limited, since they can only detect tumor lesions with relatively large margins. Ziliotto et al. [7] emphasized another barrier to surgery therapy that is the fact that some dog owners disagree with limb amputation. In that context, the care manager should clearly inform the owner the upsides and downsides of the selected treatment. The downsides include hair loss, fatigue, pain and nausea, for example.

\section{Chemotherapy}

Limb amputation followed by chemotherapy was employed in $59 \%$ of the cases used in this review. There was trend was observed in these studies in order to improve the chemotherapy response using a combination of different drugs, as reported in the studies by Chun et al. [11], Bailey et al. [19], McMahon et al. [12], and Selmic et al. [19]. Chun et al. [11] consider that chemotherapy is promising when using cisplatin and doxorubicin, but suggest a study with a larger number of animals. Bailey et al. (2003) and Selmic et al. (2014) used either carboplatin or doxorubicin, alone or in combination, but did not observed a significant difference in the treatment efficacy. One hypothesis when comparing these three studies is that cisplatin has a greater therapeutic effect. McMahon et al. [12], in turn, used carboplatin association with gemcitabine, which is indicated for the treatment of bladder cancer and locally advanced or metastatic pancreatic adenocarcinoma. In addition, it is assumed that its cytotoxic action is related to the inhibition of DNA synthesis.28 Additionally to these studies, DeRegis et al. [24] evaluated that initiating chemotherapy two or ten days after surgery did not improve the prognosis of patients and alert for the search of a safe starting dose in order to reduce toxicity.

\section{Radiation Therapy}

Radiation therapy is also used as an adjuvant treatment for pain relief and/or local control. Mantovani et al. [5], with the aim of improving the results of this therapy, since osteosarcoma cells are historically resistant to ionizing radiation, combined Erlotinib, a selective epidermal growth factor (EGFR) inhibitor, with radiation therapy in its study in vitro, noting that Erlotinib promoted a modest increase in the therapeutic effects of radiation therapy. Another in vitro study by Cannon et al. [26] makes use of aurora kinase inhibitors, which is essential for cell proliferation. However, as reported by authors, these inhibitors have not been shown to be effective alone. It is possible that the combination of these inhibitors with chemotherapy and radiation therapy may provide more satisfactory results by increasing cells the sensitivity to treatments. Furthermore, Dickerson et al. [22] report that due to the prevalence of metastases, the use of radiation therapy for local control alone is not enough. Therefore, it is necessary to combine radiation therapy with chemotherapy. Despite the advances in this area, Wycislo and Fan [3] comment that the survival time of both dogs and humans diagnosed with high grade OSA has not changed in the last two decades, since the main cause of death in these patients was due to the metastases in the lung, culminating pulmonary diseases. These authors further report that OSA is highly immunogenic, so that immunotherapy could pose a promising therapy in the future.

\section{Molecular Biology and the Search of Biomarkers of the Tumoral Phenotype of OSA}

Following the chronology of the discoveries in the area, combined with the advances in molecular biology studies and technologies in biotechnology, one can see how important it is to find biomarkers predictors of the disease. In this context, O'Donoghue et al. [6] believe that the reason tumors within the same histological type respond differently to the treatments is due to different genetic mechanisms that may be operating, thus altering the response to chemotherapy and metastatic capacity in some tumors. In other words, different responses can be considered to be differentially affect the phenotype of these cells. Therefore, the tumors gene expression analysis could elucidate new therapeutic targets leading to personalized treatments, as presented by the study of Monks et al. [16] which showed that it is possible to provide a report to the veterinarian from a single biopsy from amputation of the affected limb within 5 days. In relation to the study by O'Donoghue et al. [6], we explored differences in gene expression between primary tumors of OSA of dogs with disease-free interval (DFI) less than 100 days and greater than 300 days after chemotherapy.

One of the observations of these authors in the analysis of biomarkers was the significant reduction of Insulin-like Growth Factor (IGF2R) in the DFI group $<100$ days, with IGFs being part of a complex system Used by cells to communicate with their physiological environment. Selvarajah et al. [25] evaluated the proteic levels of 
Heat Shock Proteins (HSP) in dogs with osteosarcoma, since these proteins may have cytoprotective effects on neoplastic cells. They found that an overexpression of HSP60 (HSP, $60 \mathrm{kDa}$ ) is associated with a poor prognosis and state that these proteins should be further studied as new therapeutic targets. Following this idea, Wittenburg et al. [17] performed an in vitro study with histone deacetylase inhibitors (HDACi) and valproic acid (VPA), identifing that the most altered metabolic pathway is the oxidative phosphorylation. In addition, they show that VPA is capable of upregulating the oxidoreductase NQO1, leading to increased sensitivity of cells to the NQO1 substrate drug mitomycin $\mathrm{C}$, due to an increase enzymatic activity. Additionally, Kirpensteijn et al. [25] refer to alkaline phosphatase, which indicates an increase in bone formation activity, so that alkaline phosphatase levels could be used to evaluate the prognosis, since they may be related to the occurrence of metastases. Furthermore, Garzotto et al. [21] showed that the survival of dogs undergoing surgery followed by chemotherapy was higher in animals with normal levels of total alkaline phosphatase serum activity and the same derived from bone. Kirpensteijn et al. [25] subsequently conducted a study in 2008 in which they observed that dogs with a mutation in the TP53 gene, enconding a protein that regulates cell proliferation, DNA repair and apoptosis, have a significantly lower survival than those without mutation.

In this perspective, Murphy et al. [1] worked with the hypothesis that $\mathrm{P} 16$ gene expression in dogs with OSA was predictive of prognosis after surgery followed by chemotherapy. These authors observed that dogs negative for P16 had higher DFI and survival time than those without any evidence of P16, i.e., lack of expression may be related to lower DFI. On the other hand, Kow et al. [9] bet on the study of telomerase, since it plays a fundamental role in cellular senescence and cancer. The authors suggest that the use of telomerase inhibition therapies may be useful in dogs with OSA, due to the high degree of telomerase-positive identified. In order to use more accessible techniques, Sottnik et al. [23] state that although more studies are needed, the patients' follow up using blood counts could be used to aid in the evaluation of the therapeutic protocol and the prognosis of dogs with appendicular OSA, since myelosuppression, for example, may be induced by chemotherapeutic agents or by radiation therapy.

Biller et al. [27] show that T-cell effector $(\mathrm{CD} 4+$ and CD8 +) and regulatory (Treg) cells are responsible for both $\mathrm{T}$ lymphocytes and tumors. This study, the percentage and number of Treg, CD4+ and CD8+ cells were measured in blood by flow cytometry in lymph nodes and tumors by flow cytometry and compared between dogs with OSA and clinically healthy. It was found that dogs with OSA had significantly less circulating effector $\mathrm{T}$ cells and more Treg compared to healthy animals. In addition, in dogs with OSA the reduction of effector $\mathrm{T}$ cells was associated with a shorter survival time, encouraging further studies in this area [30].

\section{Paraneoplastic Syndromes and Cancer Patient Care}

In order to a therapeutic protocol be efficient, it should take into consideration not only the therapy employed itself, but also the patient well-being. Like humans, animals do not only suffer from tumors, but also with paraneoplastic syndromes, that are induced by the tumor including a diverse group of endocrine, neurological, mucocutaneous and hematological clinical manifestation $[31,32]$. This patient care is already well established in human medicine with the treatment of pain, caring for nutrition and encouraging the practice of physical activities. Ciccone et al. [29], for example, observed an improvement in the clinical picture of patients with cardiovascular diseases who improved their life habits with a healthy diet combined with regular physical exercise and stopping or decreasing cigarette consumption.

However, in veterinary medicine, especially in developing countries, basic care has not yet been widely implemented, although it is known that surgery, chemotherapy and radiation therapy can cause direct or indirect deleterious effects on the patient's nutritional status, for example, leading to anorexia, and food aversion $[31,33]$. Furthermore, malnutrition can impair the immune system and consequently increase the risk of infection, as well as reduce muscle tissue and, consequently, decrease and/or difficult the mobility, which may also be reduced due to pain [31,32,34]. In this context, the care manager is an essential practitioner to present ways of implementing behavior changes beneficial to the patient's health and to continuously inform the medical staff about the patients' health status in order to improve their prognosis. Therefore, in veterinary medicine, with this same objective, the work of this professional should become more present.

\section{Conclusion}

Cytopathological and imaging tests provide rapid results for both diagnoses of osteosarcoma and for the investigation of metastases, being a fundamental tool for diagnosis. However, histopathological examination should not be disregarded, because in case of doubt regarding the diagnosis, surgeries will not be performed without necessity. Despite the observed changes in treatment, either by combining therapies, investigating differentially expressed genes or using substances that may increase the efficiency of therapies already used, the survival of animals has not increased significantly.

Therefore, studies should be conducted in order to seek new diagnostic and therapeutic approaches to this highly aggressive disease that affects both dogs and humans, contributing to research in comparative oncology, especially considering the advances in molecular biology tools in the search for specific biomarkers, bringing specificity to the treatment and reduction of unexpected side effects.

\section{Funding Information}

Investigative and Comparative Pathology Laboratory.

\section{References}

1. Murphy BG, Mok MY, York D, Rebhun R, Woolard KD, et al. (2017) Evaluation of P16 expression in canine appendicular osteosarcoma. BMC Veterinay Research.

2. Gouvêa AS, Lichtler J, Scherer S, Mombach VS, Reis KDHL, et al. (2016) Pedicle frozen autograft for limb sparing surgery in a dog with femoral osteosarcoma. Ciência Rural, Santa Maria 46: 2206-2209.

3. Wycislo KL, Fan TM (2015) The Immunotherapy of Canine Osteosarcoma: A Historical and Systematic Review J Vet Intern Med 29: 759-769.

4. Sabattini S, Renzi A, Buracco P, Defourny S, Garnier-Moiroux M, et al. (2017) Comparative Assessment of the accuracy of Cytological and Histologic Biopsies in the Diagnosis of Canine Bone Lesions. J Vet Intern Med 31: 864-871.

5. Mantovani FB, Morrison JA, Mutsaers AJ (2016) Effects of epidermal growth factor receptor kinase inhibition on radiation response in canine osteosarcoma cells. BMC Veterinary Research. 12: 82.

6. O'Donoghue LE, Ptitsyn AA, Kamstock DA, Siebert J, Thomas RS, et al. (2000) Expression profiling in canine osteosarcoma: identification of biomarkers and pathways associated with outcome. BMC Cancer 10: 506.

7. Ziliotto L, Fantinatti AP, Daleck CR, Filho JGP, Souza AP, et al. (2003) Use of allogeneic cortical bone implant preserved in glycerin for preservation of the thoracic limb. Experimental study in dogs. Acta Cirúrgica Brasileira, 18: 107.

8. Ferrigno CRA, Campos AG, Stopigli AJ, Fantoni DT (2008) Total articulated 
Citation: de Sanctis P, Caetano BFR, Flórez LMM, de Souza VB, Zambuzzi WF, et al. (2017) Osteosarcoma in Dogs: Diagnosis and Treatment - A Literature Review. J Cytol Histol 8: 473. doi: 10.4172/2157-7099.1000473

prodthesis for treatment of appendicular osteosarcoma in a dog. Ciência Rural 38: 8 2379-2382

9. Kow K, Thamm DH, Terry J, Grunerud K, Bailey SM, et al. (2008) Impact of Telomerase Status on Canine Osteosarcoma Patients. J Vet Intern Med 22: 1366-1372.

10. Kirpensteijn J, Kik M, Teske E, Rutteman GR (2008) TP53 Gene Mutations in Canine Osteosarcoma. Veterinary Surgery $37:$ 454-460.

11. Chun R, Kurzan ID, Couto CG, Klausner J, Henry C, et al. (2000) Combination Chemotherapy for the Treatment of Canine Osteosarcoma: A Pilot Study. J Vet Intern Med 14: 495-498.

12. McMahon M, Mathie T, Stingle N, Romansik E, Vail D, London C (2011) Adjuvant Carboplatin and Gmcitabine Combination Chemotherapy Postamputation in Canine Appendicular Osteosarcoma. J Vet Intern Med 25: 511-517.

13. Talbott JL, Boston SE, Milner RJ, Lejeune A, Souza CHM, Kow K, et al. (2015) Retrospective Evaluation of Whole Body Computed Tomography for Tumor Staging in Dogs with Primary Appendicular Osteosarcoma. Veterinary Surgery 46: $75-80$.

14. Karnik KS, Samii VF, Weisbrode SE, London CA, Green EM (2012) Accuracy of Computed Tomography in determining lesion size in Canine Appendicular Osteosarcoma. Vet Radiol Ultrasound 53: 3.

15. Kirpensteijn J, Kik M, Rutteman GR, Teske E (2002) Prognostic Significance of a New Histologic Grading System for Canine Osateosarcoma. Vet Pathol 39: $240-246$

16. Monks NR, Cherba DM, Kamerling SG, Simpson H, Rusk AW, et al. (2013) A multi-site feasibility study for personalized medicine in canines with Osteosarcoma. Journal of Translational Medicine. 2013 11: 158.

17. Wittenburg LA, Ptitsyn AA, Thamm DH (2012) A Systems Biology Approach to Identify Molecular Pathways Altered by HDAC Inhibition in Osteosarcoma. J Cell Biochem 113(3): 773-783.

18. Teixeira LV, Lopes STA, Martins DB, França RT, Fighera RA (2010) Fineneedle aspiration cytology as sampling method for histopathology in canine osteosarcoma. Pesq Vet Bras 30(2): 145-148.

19. Selmic LE, Burton JH, Thamm DH, Withrow SJ, Lana SE (2014) Comparison of Carboplatin and Doxorubicin-Based Chemotherapy Protocols in 470 Dogs after Amputation for Treatment of Appendicular Osteosarcoma. J Vet Intern Med 28: 554-563.

20. Bailey D, Erb H, Willians L, Ruslander D, Hauck M (2003) Carboplatin and Doxorubicin Combination Chemotherapy for the Treatment of Appendicular Osteosarcoma in the Dog. J Vet Intern Med. 17: 199-205.
21. Garzotto CK, Berg J, Hoffmann WE, Rand WM (2000) Prognostic Significance of Serum Alkaline Phosphatase Activity in Canine Appendicular Osteosarcoma. J Vet Intern Med 14: 587-592.

22. Dickerson ME, Page RL, LaDue TA, Hauck ML, Thrall DE (2001) Retrospective Analysis of Axial Skeleton Osteosarcoma in 22 Large-Breed Dogs. J Vet Intern Med 15: 120-124.

23. Sottnik JL, Rao S, Lafferty MH, Thamm DH, Morley OS, et al. (2010) Association of Blood Monocyte and Lymphocyte Count and Disease-Free Interval in Dogs with Osteosarcoma. J Vet Intern Med 24: 1439-1444.

24. DeRegis CJ, Moore AS, Rand WM, Berg J (2003) Cisplatin and Doxorubicin Toxicosis in Dogs with Osteosarcoma. J Vet Intern Med 17: 668-673.

25. Selvarajah GT, Bonestroo FAS, Kirpensteijn J, Kik MJL, Zee R, et al. (2013) Heat shock protein expression analysis in canine osteosarcoma reveals HSP60 as a potentially relevant therapeutic target. Springer, Cell Stress Society International 18: 607-62.

26. Cannon CM, Pozniak J, Scott MC, Ito D, Gorden BH, et al. (2015) Canine Osteosarcoma Cells Exhibit Resistance to Aurora Kinase Inhibitors. Vet Comp Oncol 13: 48-59.

27. Biller BJ, Guth A, Burton JH, Dow SW (2015) Decreased Ratio of CD8+ T Cells to Regulatory T Cells Associated with Decreased Survival in Dogs with Osteosarcoma. J Vet Intern Med 24: 1118-1123.

28. Gemzar® [directions]. São Paulo (2013) D.C.B. 04420

29. Ciccone MM, Aquilino A, Cortese F, Scicchitano P, Sassara M, et al. (2010) Feasibility and effectiveness of a disease and care management model in the primary health care system for patients with heart failure diabetes (Project Leonardo). Vasc Health Risk Manag. 6: 297-305.

30. Volpato LER, Silva TC, Oliveira TM, Sakai VT, Machado MAAM (2007) Radiation therapy and chemotherapy-induced oral mucositis. Rev Bras Otorrinolaringol 73: 562-566.

31. Oliveira KM, Horta RS, Silva CMO, Lavor SL (2013) Main Paraneoplastic Syndromes in Dogs and Cats - a Literature Review. Enciclopédia Biosfera 9: 2073-2089.

32. Garcia AL, Mesquita J, Nóbrega C, Vala H (2016) Palliative care in veterinary oncology. J Education, Techologies, and Health 37: 14

33. Saker K (2014) Pratical Approaches to Feeding the cancer patient. Today's Veterinary Practice ACVN Nutrition Notes.

34. Timothy A, Giridhar MNV, Razavi GS (2015) Principles of Nutritional Support in Cancer Patients. J Cancer Sci Res 1: 014. 